\title{
Upgrading the Fe Grade of Magnetite Concentrate Using a Magnetic Hydro-Sizer
}

\author{
Evans Vincent Rissenga ${ }^{1}$, Willie Nheta ${ }^{1}$ \\ ${ }^{1}$ University of Johannesburg, Department of Metallurgy, Faculty of Engineering and the Built Environment. Mineral \\ Processing and Technology Research Centre. P.O Box 524 Auckland 2006, Johannesburg, South Africa. \\ evrissenga@gmail.com; wnheta@uj.ac.za
}

\begin{abstract}
In this study, a magnetic hydro-sizer was used to upgrade the final Fe concentration grade of a magnetite ore. The impact of the magnetic field intensity and water flow rate on the concentration grade were investigated. The chemical composition, mineralogical phases and surface topography of the feed to the hydro-sizer were analysed using XRF, XRD and SEM respectively. The results revealed that the feed to the magnetic hydro-sizer contained $61.25 \% \mathrm{Fe}$. Major phases in the feed are magnetite, hongquiite, calcium magnesium catena-silicate and quartz. SEM results showed that the sample was well liberated. A concentrate containing $63.9 \% \mathrm{Fe}$ was produced whilst operating at particle size distribution of $80 \%$ passing $180 \mu \mathrm{m}$, water flow rate of $290 \mathrm{~m}^{3} / \mathrm{hr}$ and a magnetic intensity of 1350gauss. The higher the magnetic intensity, the lower the Fe grade of the concentrate. The higher the water flow rate, the higher the Fe grade of the concentrate. For a magnetic hydro-sizer, operating field should be between 1200 and 1350 gauss and a water flow rate above $260 \mathrm{~m} 3 / \mathrm{hr}$ for the final concentration of magnetite.
\end{abstract}

Keywords: Magnetic separation, magnetite, low grade iron ore, magnetic hydro-sizer

\section{Introduction}

Iron forms the bases for the development of the steel industry. Due to increase in demand of steel in recent years in countries such as China, India and Malaysia, gradual depletion of high-grade magnetite ores has been noticed leading to the exploitation of low-grade ores worldwide [1]. However, processing of low-grade magnetite ores is characterised by poor separation efficiencies due to poor liberation and complexity of the ore. Magnetite is strongly magnetic and magnetic separation is generally applied in the beneficiation process of magnetic ores [2]. Magnetic separation is one of the methods that has been used for almost 200 years in the concentration of iron ores and is still used extensively even today. Most common used magnetic separation process is carried out on a drum separator [3].

Magnetite is commonly produced as a by-product from processing of phosphate and copper minerals. The phosphate and copper minerals are recovered using flotation process, producing a rich concentrate of phosphate and copper minerals, and tailings containing most of the magnetite [4]. The tailings can be treated further to recover magnetite through a series of magnetic separation circuits [5]. The efficiency of separation on drum magnetic separators is not determined by magnetic field but rather by the product of the magnetic induction and the field gradient. As a result, they are not a good concentrating equipment for the final concentrate.

A hydro-sizer is a classifier used in mineral processing to classify material in terms of the physical properties of a particle such as the particle size and density of the particle [6]. Water plays an important role in hydro-sizer as it is used to dilute the slurry to improve concentration of the denser particles from the lighter particles. However, a hydro-sizer can be modified by addition of magnets (magnetic field) and separation will be depended on particle size, density, and magnetic susceptibility. Separation of particles in a solution using a magnetic field is more selective and efficient and often much faster than centrifugation or filtration. The efficiency of a magnetic hydro-sizer is affected by the rate of water injection into the hydrosizer, feed density, particle size distribution, particle density and magnetic intensity of the magnetic units [7].

In this paper, the potential of using a magnetic hydro-sizer for the final upgrading of magnetite concentrate is presented. The research focused on the effect of magnetic intensity, particle size distribution and dilution water feed rate into the magnetic hydro-sizer on the Fe grade of the final concentrate. 


\section{Methodology}

\subsection{Materials}

Magnetite ore samples used for the research are from the slimes dam at Phalaborwa Foskor mine, South Africa. Foskor treats phosphate ore using flotation process and their tailings material contains 45 to $53 \% \mathrm{Fe}$ in the form of magnetite. The magnetic ore sample used comprised of Silicon Oxide(1,0,1) Magnetite, syn $(2,2,2)$, Hongquiite $(1,1,1)$, diopside high, Calcium magnesium catena-silicate $(1,3,1)$ and most importantly Magnetite, $\operatorname{syn}(5,1,1)$, which has the metal of value as iron (Fe),with an overall percentage of $46.9 \% \mathrm{Fe}$.

\subsection{Methods}

The industrial test was carried out at a South African Ore Beneficiation (SAOB) plant. The plant was stabilised in preparation for sample campaign and all spillage pumps running were stopped. Sampling condition were divided into three condition for this research, which included the different magnetic field intensity, grind and water injection into the magnetic hydro-sizer. Particle size distribution (PSD) analysis was done to determine the optimum grind at which most of the non-magnetic minerals are separated from the magnetic minerals. PSD was determine using screen sieves and sieve shaker in the laboratory. Chemical composition of the samples was determined using X-ray fluorescence (XRF).

The mineralogical phases for the three samples: run of mine (ROM), feed to the magnetic Hydro-sizer and underflow (U/F) which is the final product from the magnetic hydro-sizer, were identified using an X-Ray Diffraction7000 , shimadzu corp., China operated at the wavelength of $0.154060 \mathrm{~nm}$, generated at 20KV and $30 \mathrm{~mA}$ using $\mathrm{Cu} \mathrm{K \alpha}$ radiation. Scanning was conducted at 2 minutes for 2 theta $(\theta)$ values between 10 and 90 degrees.

\subsubsection{The impact of Magnetic intensity on Fe grade of the final concentration.}

The impact of high magnetic intensity on the Fe grade of the final concentration was investigated by operating the magnetic hydro-sizer with varying intensities from 1400 Gauss to 1460 Gauss. The feed PSD were kept constant at $80 \%$ passing $180 \mu \mathrm{m}$ and the water injection flow rate at $290 \mathrm{~m}^{3} / \mathrm{hr}$. Samples collected from the concentrate were analyzed using XRF.

The impact of low magnetic intensity on the Fe grade final concentration was investigated by varying magnetic intensity from 1350 gauss to 1400 gauss. Once again, the water flow rate and Feed PSD were kept constant at $290 \mathrm{~m}^{3} / \mathrm{hr}$ and $240 \mathrm{~m}^{3} / \mathrm{hr}$, respectively. The concentrate samples at each intensity were collected and analysed using XRF.

\subsubsection{Impact of dilution water flow rate on Fe grade of the final concentration.}

The impact of dilution water flow rate on Fe grade of the final concentration was investigated by varying the dilution water flowrate from $240 \mathrm{~m}^{3} / \mathrm{hr}$ to $290 \mathrm{~m}^{3} / \mathrm{hr}$. Magnetic intensity and PSD of feed was kept constant at 1360 Gauss and $80 \%$ passing $180 \mu \mathrm{m}$, respectively. Samples of the feed, concentrate and tailings were collected at each flowrate and analysed using XRF and SEM.

\section{Results and discussion}

3.1 Sample Characterisation

The feed to the hydro-sizer was analysed for elemental composition and the results are shown in Table 1. From Table 1, it can be seen that the Fe content of hydro-sizer feed was $62.129 \%$ which is below the required target of $63.5 \%$ Fe. The results also show that major contaminants are $\mathrm{Ti}(2,734 \%), \mathrm{Mg}(2,085 \%)$ and $\mathrm{Si}(1,91 \%)$. Titanium minerals are paramagnetic, and they can be recovered into the concentrate with the increase in magnetic intensity. Mg and Si minerals are diamagnetic, and they can only be recovered into the concentrated through entrainment [8]. 
Table 1: Elemental composition of the hydro-sizer feed

\begin{tabular}{|l|c|c|c|c|c|c|c|c|}
\hline Element & $\mathrm{O}$ & $\mathrm{Fe}$ & $\mathrm{Mg}$ & $\mathrm{Al}$ & $\mathrm{Si}$ & $\mathrm{Ca}$ & $\mathrm{Ti}$ & $\mathrm{Mn}$ \\
\hline \% Wt & 30.1 & 62,129 & 2,085 & 0,052 & 1,91 & 0,684 & 2,734 & 0,306 \\
\hline
\end{tabular}

\subsection{Mineralogical Composition of the Feed to the Hydro-Sizer}

The mineralogical composition of the ROM, feed to the hydro-sizer and the hydro-sizer underflow was determined using $\mathrm{XRD}$ and the results are shown in Fig. 1. Major mineral phases in the ROM are quartz and calcium magnesium catena silicate ( $\mathrm{Ca} \mathrm{Mg} \mathrm{Si2} \mathrm{O6)} \mathrm{which} \mathrm{are} \mathrm{diamagnetic,} \mathrm{magnetite} \mathrm{(Fe3O4)} \mathrm{which} \mathrm{is} \mathrm{ferromagnetic} \mathrm{material} \mathrm{and} \mathrm{hongquiite} \mathrm{(TiO)} \mathrm{which} \mathrm{is}$ paramagnetic [9]. Most of the silicate minerals are removed during the first stages of magnetic separation using a drum magnetic separator prior to the upgrading using the hydro-sizer.

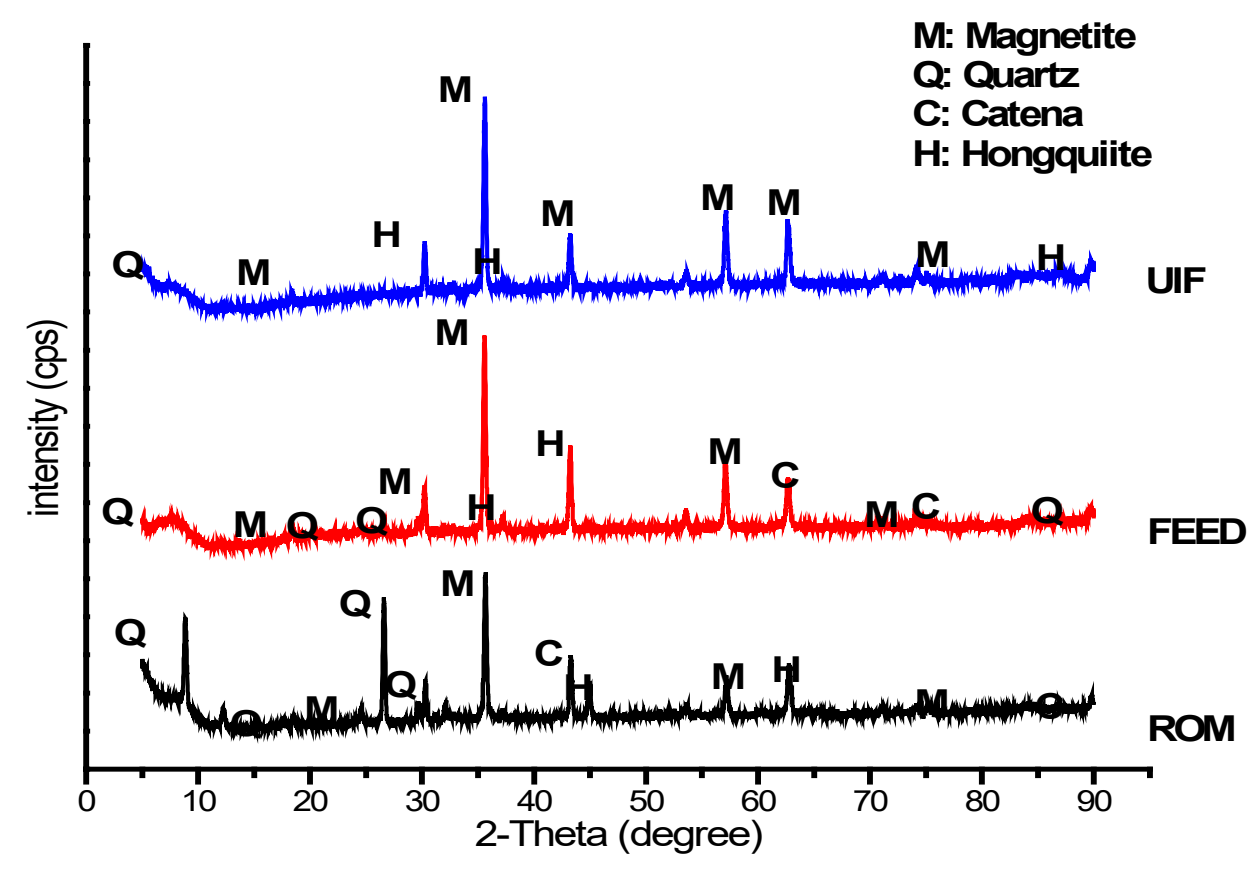

Fig. 1: XRD pattern for ROM, hydro-sizer Feed and Underflow (U/F) 


\subsection{Elemental Analysis and Mineral Distribution in the Feed to the Hydro-Sizer Samples}

Microstructural characterization was carried out by optical microscopy (Keyence VH-Z50L) and scanning electron microscopy (Tescan VEGAIILMH) (SEM). A commercial image analysis software was employed for quantitative measurement of the microstructure parameters.

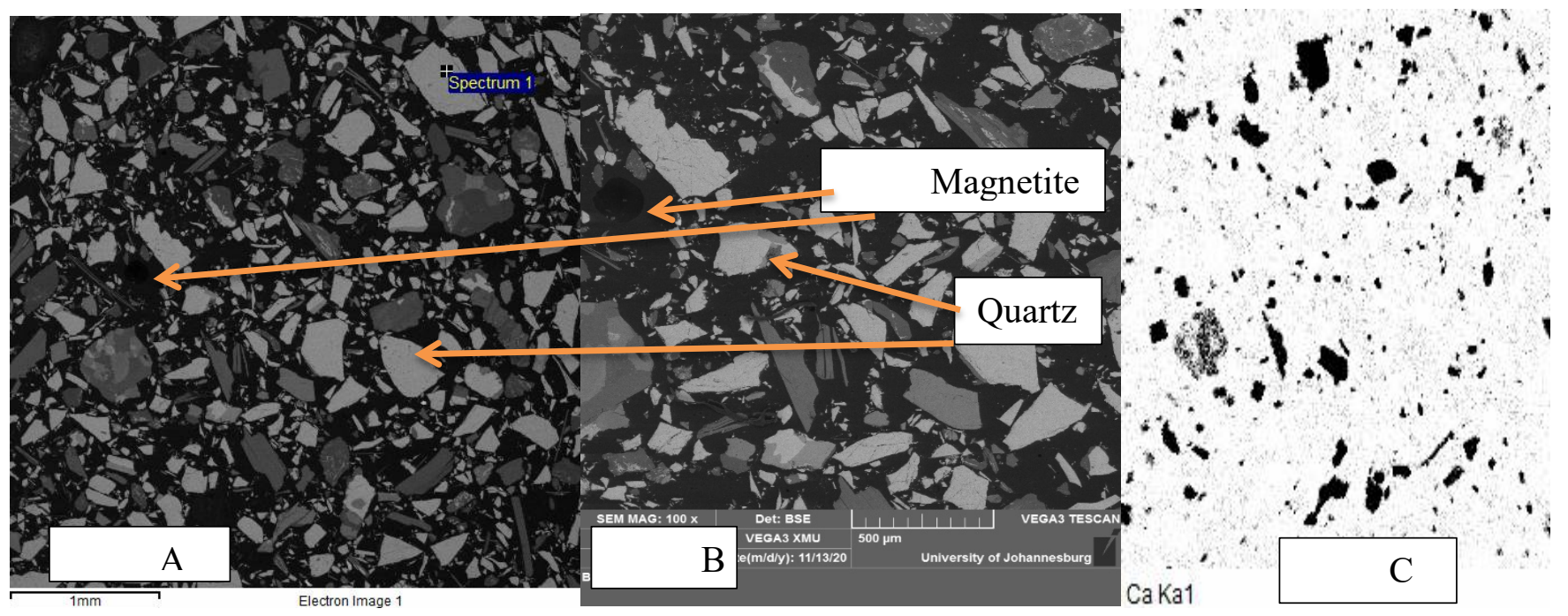

Fig. 2: The hydro-sizer feed sample topography as obtained from SEM and EDS scan.

Different phase structures were determined, mostly magnetite phases and quartz. The SEM micrographs of Fig. 2 (a)-(c) present a general view of the tensile deformed microstructures ( $\varepsilon=5 \%, 10 \%$ and $20 \%$, respectively). Ultrafine basket-weave microstructural characteristic, with the width of $\alpha$ laths about $1.5 \mu \mathrm{m}$ was observed. The microstructure of the magnetite and gangue minerals observed via optical microscopy are presented in Fig. 2. Based on the statistical results derived via an optical microscopy, the fine microstructure observed was mostly at a content of about $79.8 \%$ magnetite, $5.86 \%$ silica and $0.345 \%$ hongquiite and other minerals.

\subsection{The Impact of Magnetic Intensity on Fe Grade of the Final Concentrate}

The impact of magnetic intensity on Fe grade of the final concentrate was investigated and the results are shown in Fig. 3. It can be seen that the higher the intensity the lower the grade. This can be due to the paramagnetic material reporting into the final concentrate as well as entrainment of diamagnetic particles. Apart from magnetic intensity, magnetic field orientation plays a vital role on the performance of a magnetic separator [10]. The best results of $63.53 \%$ Fe were obtained at a magnetic intensity of about 1200 gauss and at $290 \mathrm{~m}^{3} / \mathrm{hr}$ flowrate, which indicated an iron upgrade of about $1.4 \%$ iron in the product from the hydro-sizer feed. 


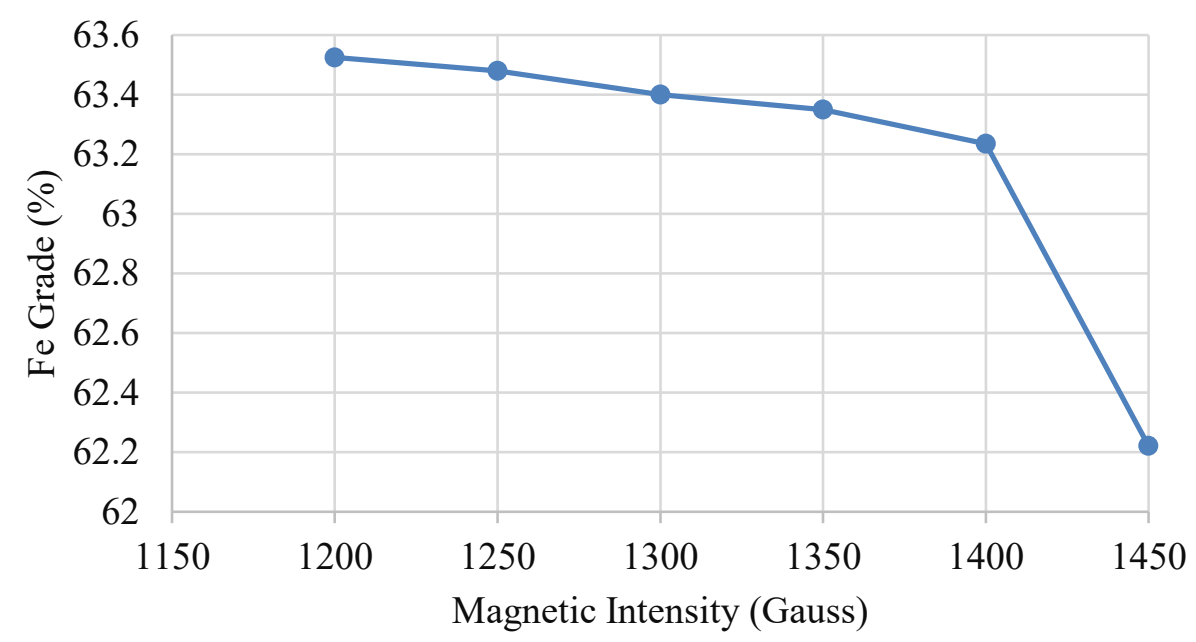

Fig. 3: Impact of magnetic intensity on the Fe grade of the final concentrate, $290 \mathrm{~m}^{3} / \mathrm{hr}$ flowrate

\subsection{The Impact of Dilution Water Flow Rate on the Fe Grade of the Concentrate}

The impact of dilution water flow rate was investigated, and the results are illustrated in Fig. 4. As the water flow rate increased from $240 \mathrm{~m}^{3} / \mathrm{hr}$ to $290 \mathrm{~m}^{3} / \mathrm{hr}$, the Fe grade in the final concentrate increased from $62.2 \%$ to $63.9 \%$ respectively. The dilution flow rate into the magnetic hydro-sizer plays a very important role in the upgrading of magnetite where a steady increase on grade is seen as the flowrate into the separator is increased. High water flowrate into the hydro-sizer increases the safe area of the material thus reducing the possibility of entrainment of the non-magnetic materials, like silica. The nonmagnetic fines are thus overflown with the hydro-sizer overflow, leaving huge improvement in the grade of iron reporting to the final concentrate. The results have shown an improvement of above $1.7 \%$ in Fe grade.

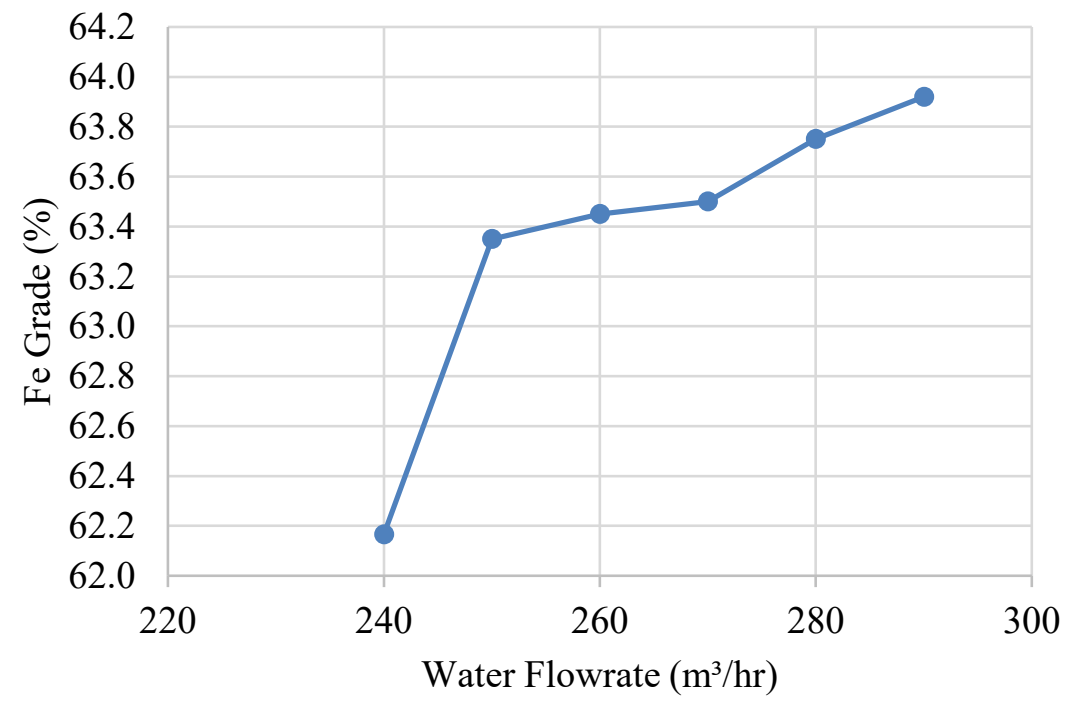

Fig. 4: Impact of water flowrate injected into the hydro-sizer on the Fe grade of final concentrate, 1350 gauss. 


\subsection{The effect of grind on the recovery and grade of Fe}

The effect of grind was investigated, and it was found that grind can play an important role on the upgrading of iron in the concentrate grade, as shown in Fig. 5. The result shows as the amount of solid passing the $180 \mu \mathrm{m}$ increased, the iron grade of the final concentrate improved. Fine grind results in the liberation of the nonmagnetic material locked in the magnetic materials, which can report into the final product because they were associated with the magnetic material.

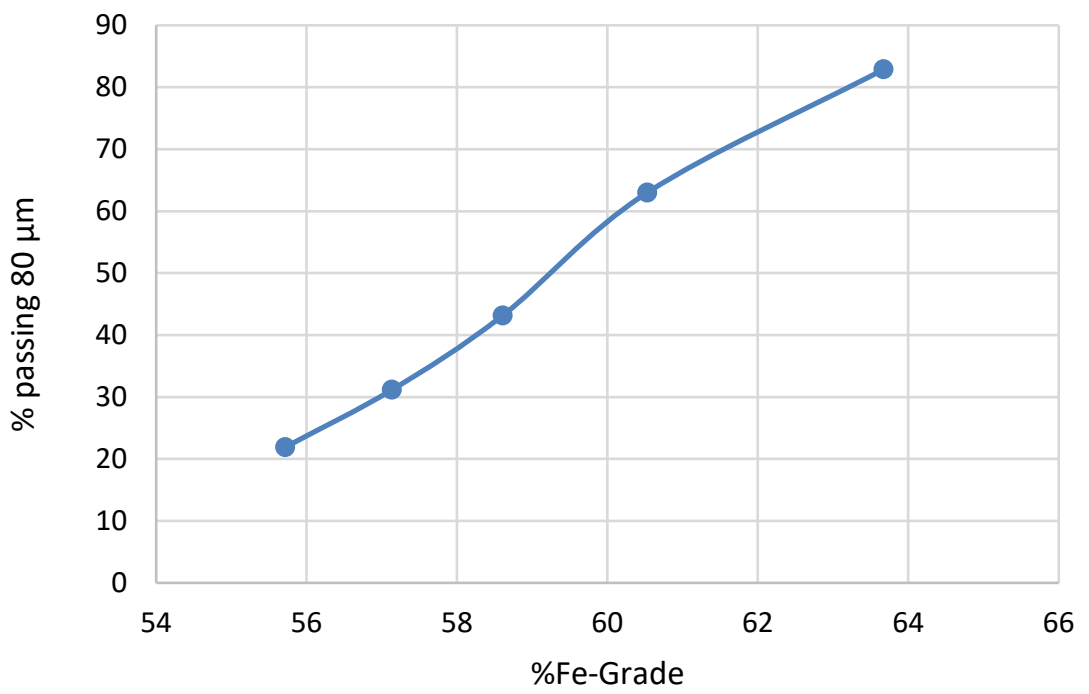

Fig. 5: Impact of PSD on the Fe Grade of the final concentrate, 1350 Gauss, $290 \mathrm{~m}^{3} / \mathrm{h}$ water flowrate.

\section{Conclusion}

The results have shown that the major mineralogical phases in the hydro-sizer feed are magnetite, calcium magnesium catena silicate, hongquiite and quartz. Most of the titanium (IV) oxide was incorporated into the concentrate with the increase in the magnetic intensity. At particle size distribution of $80 \%$ passing $180 \mu \mathrm{m}$, water flowrate of $290 \mathrm{~m}^{3} / \mathrm{h}$ and magnetic intensity of 1360 gauss, a concentrate containing 63.9\% Fe was produced. For a magnetic hydro-sizer, operating field should be between 1200 and 1350 gauss and a water flow rate above $260 \mathrm{~m} 3 / \mathrm{hr}$ for the final concentration of magnetite. The effect of grind on the upgrading of iron in the final concentrate has shown that the finer the grind the better the separation of magnetite, which then improve iron in the final concentrate. With the correct operating conditions, a magnetic hydro-sizer can be used to upgrade the final concentrate of a magnetite concentrating plant. Further studies need to target the interactive effects of the water flowrate and magnetic intensity on the recovery and grade of magnetite using the design of experiments (DoE) approach.

\section{Acknowledgements}

The authors would like to acknowledge University of Johannesburg, and NRF for sponsorship and financial support of this research.

\section{References}

[1] Y. Sun, W. Zhou, Y. Han and Y. Li, "Strengthening liberation and separation of magnetite ore via magnetic pulse pretreatment: An industrial test study.," Advanced Powder Technology, vol. 31, no. 5, pp. 2101-2109, 2020.

[2] V. Ponomar, O. Brik, Y. Cherevko and V. Ovsienko, "Kinetics of hematite to magnetite transformation by gaseous reduction at low concentration of carbon monoxide.," Chemical Engineering Research and Design, vol. 148, pp. 393402, 2019. 
[3] L. Zhang, F. Weigler, V. Idakiev, Z. Jiang, L. Mörl, J. Mellmann and E. Tsotsas, "Experimental study of the particle motion in flighted rotating drums by means of Magnetic Particle Tracking," Powder technology, vol. 339, pp. 817-826, 2018.

[4] Y. Liu and L. Huang, "Magnetite recovery from copper tailings increases arsenic distribution in solution phase and uptake in native grass," Journal of environmental management, Vols. 186,, pp. 175-182, 2017.

[5] W. Nheta, T. Lubisi, S. Masemola and M. Makhatha, "Beneficiation of haematite from fluorspar tailings by reverse flotation.," in In Proceedings of the World Congress on Mechanical, Chemical, and Material Engineering, Barcelona, 2015.

[6] D. David, M. Larson and Li, M , "Optimising Western Australia magnetite circuit design," in Proceedings of the Metallurgical Plant Design and Operating Strategies, Perth, 2011.

[7] S. Liu, Y. Zhao, W. Wang and S. Wen, "Beneficiation of a low-grade, hematite-magnetite ore in China," Mining, Metallurgy \& Exploration, vol. 31, no. 2, pp. 136-142, 2014.

[8] S. Tripathy, Y. Murthy, V. Singh and N. Suresh, "Processing of ferruginous chromite ore by dry high-intensity magnetic separation," Mineral Processing and Extractive Metallurgy Review, vol. 37, no. 3, pp. 196-210., 2016.

[9] V. Singh, , S. Batra and I. Sharma, "Rietveld analysis for crystal structure determination of polycrystalline materials.," Materials Today: Proceedings, vol. 29, pp. 832-835, 2020.

[10] L. Chen, "Effect of magnetic field orientation on high gradient magnetic separation performance.," Minerals Engineering, vol. 24(1), pp. 88-90, 2011. 